\title{
ABET \& Engineering Accreditation - History, Theory, Practice: Initial Find- ings from a National Study on the Governance of Engineering Education
}

\author{
Dr. Atsushi Akera, Rensselaer Polytechnic Institute
}

Atsushi Akera is Associate Professor and Graduate Program Director in the Department of Science and Technology Studies at Rensselaer Polytechnic Institute (Troy, NY). He received his M.A. and Ph.D. in the History and Sociology of Science, University of Pennsylvania. His current research is on the history of engineering education reform in the United States (1945-present). He is a the immediate past chair of the ASEE Ad Hoc Committee on Interdivisional Cooperation; Chair of the International Network for Engineering Studies (INES); past chair of the ASEE Liberal Education / Engineering and Society Division; and a former member of the Society for the History of Technology's (SHOT) Executive Council. Publications include /Calculating a Natural World: Scientists, Engineers and Computers during the Rise of U.S. Cold War Research/ (MIT Press, 2006).

Sarah Appelhans, University at Albany

Sarah Appelhans is a PhD candidate in Cultural Anthropology. Her dissertation research, "Steel Toes and Ponytails: Gender and Belonging in Engineering", investigates the boundaries of membership in engineering in the Capital District of New York. She is honored to be a research assistant on the NSFsponsored study on engineering education reform entitled "The Distributed System of Governance in Engineering Education." In addition to her academic experience, she is a former mechanical engineer with several years of experience in the aviation and construction industries.

Dr. Alan Cheville, Bucknell University

Alan Cheville studied optoelectronics and ultrafast optics at Rice University, followed by 14 years as a faculty member at Oklahoma State University working on terahertz frequencies and engineering education. While at Oklahoma State, he developed courses in photonics and engineering design. After serving for two and a half years as a program director in engineering education at the National Science Foundation, he took a chair position in electrical engineering at Bucknell University. He is currently interested in engineering design education, engineering education policy, and the philosophy of engineering education.

\section{Thomas De Pree, Rensselaer Polytechnic Institute}

Thomas De Pree is a PhD student and HASS Fellow of Science and Technology Studies in the School of Humanities, Arts, and Social Sciences at Rensselaer Polytechnic Institute in Troy, New York. Trained in sociocultural anthropology, he received a BA in Anthropology and Psychology from the University of New Mexico in 2010, and a MA in Anthropology and Education from Teachers College, Columbia University in 2015.

\section{Dr. Soheil Fatehiboroujeni, Indiana-Purdue University}

Soheil FatehiBoroujeni received his Ph.D. in Mechanical Engineering from the University of California, Merced in 2018. As a postdoctoral researcher at Purdue University, School of Engineering Education, Soheil is working on a multi-institutional project characterizing governance processes related to change in engineering education, and pursuing other research interests in epistemology and design, among other philosophical topics in engineering education.

\section{Dr. Jennifer Karlin, Minnesota State University, Mankato}

Jennifer Karlin spent the first half of her career at the South Dakota School of Mines and Technology, where she was a professor of industrial engineering and held the Pietz professorship for entrepreneurship and economic development. She is now a research professor of integrated engineering at Minnesota State University, Mankato, and the managing partner of Kaizen Academic.

\section{Dr. Donna M. Riley, Purdue University, West Lafayette}

Donna Riley is Kamyar Haghighi Head of the School of Engineering Education and Professor of Engineering Education at Purdue University. 


\section{ABET \& Engineering Accreditation-History, Theory, Practice: Initial Findings from a National Study on the Governance of Engineering Education}

When instructors change their classroom practices — shifting from lecture to active learning for example - there is a direct impact on student learning that is relatively straightforward to measure. However, every course is also part a curriculum that is developed by the faculty, often in line with a college or university's present vision, and shaped by national values and policies surrounding engineering education and higher education. These factors have indirect but equally significant impacts on student learning, and constitute the larger ecosystem in which student learning takes place. These indirect effects are more difficult, and likely impossible, to fully understand. If the higher education system in the United States was more centrally governed by an educational ministry, as is found in Europe and elsewhere, it might be easier to understand and control the impact of these indirect factors. However, the highly decentralized system of educational governance within the U.S., and the great diversity of schools that are both the product and reasons for this ecosystem, have given rise to an extremely heterogeneous system. In the United States accreditation serves as one of the few, central mechanisms for shaping learning; it carries the weight of the state to the extent that it contributes to job and federal loan availability as well as licensure in selected fields. This paper examines the historic and presentday impact of accreditation on engineering education in the United States.

The accreditation organization that most impacts student learning in engineering education in the United States is ABET Inc., known earlier in its history as the Accreditation Board for Engineering and Technology. Like other educational governance entities (such as a state board of education), accreditation bodies can embody societal values, incorporating national agendas and even ideologies surrounding higher education and workforce development. However, the high degree of diversity within U.S. colleges and universities creates challenges for accrediting organizations like ABET. In a diverse educational ecosystem comprised of public and private institutions; general universities, engineering schools, land-grant institutions, and liberal arts colleges; and at least fifty separate state systems of higher education, how does an accreditation agency go about trying to ensure uniform standards and innovation within a national system of engineering education?

This paper takes a close look at ABET as a mechanism for educational governance, using oral and oral history interviews of personnel affiliated with ABET as well as faculty and administrators at colleges and universities influenced by their policies. The data used in this study is part of a much larger study focused on engineering education reform and governance in the United States. At the current time data is still being collected for this project, so this paper presents preliminary but key findings. The goal of the paper is to provide a lens through with readers can better understand ABET, its capacity for governance, and how this capacity has evolved over time. Given the significant ways in which past decisions about engineering accreditation continue to shape the engineering accreditation landscape today, oral histories of key participants, as well as insights gained from our broader university interviews are used to reconstruct ABET's evolving governance traditions. The study also pays attention to the organizational processes through which these changes were accomplished. Related to our goal of 
gaining a better understanding of engineering accreditation, this early presentation of our results is designed to elicit feedback in a way that can help focus the authors' efforts as further data analysis takes place. The underlying theory and method are presented first. Next a history of ABET's accreditation policies and practices, and a limited account of present-day accreditation procedures as practiced is presented to provide vital evidence related to ABET's evolving governance model. Preliminary conclusions from the data set are then presented, with open questions suggested by the analysis to date.

\section{Theory and Method}

The interpretive findings of this paper draw from the larger project, which was organized as an exploratory qualitative study of engineering education governance built around the use of grounded theory methods [1-3]. The study is built on semi-structured interviews with a multisite, multi-scale design. The interview protocol was derived from the project's seven core research questions, summarized as follows:

1. How do participants view the structure of the engineering profession and U.S. higher education as they impact engineering education?

2. What ethnomethodologically accountable (describable) body of practice exists for engineering education reform?

3. How do the epistemic habits of engineers influence their approach to engineering education reform?

4. How and to what extent are engineering educators and administrators/leaders able to articulate the social context in which reforms occur?

5. How are changes in engineering education coordinated and led; who is included and who is excluded?

6. How do the different goals and perceptions of different organizational actors shape reform processes, particularly with regards to closure of such processes.

7. How do existing arrangements then become destabilized so that further changes occur?

Our core research questions and accompanying interview questions were formulated along the lines of the project's early theoretical constructs (see below) in order to identify how different actors within and across different organizations understood their history and mission; the context for reform; the reform practices that they could recount; and a number of ancillary questions related to faculty attitudes, student experience, and visions for the future which are used primarily for triangulation. Within our interview protocol are several questions that focus specifically on how and to what extent ABET impacts the processes engineering schools use to improve their educational programs.

To date, the project has conducted around 210 interviews at 23 colleges and universities and four professional societies and organizations. Diverse representation has been maintained through a site selection matrix to ensure that public and private institutions; general universities, engineering colleges, land-grant institutions, and liberal arts colleges; women and minority serving institutions; institutions of different rank (three tiers) and geographic areas (four zones); and $\mathrm{PhD}$ and non-PhD institutions were included. Subject selection within individual sites was left partially in the hands of the institutions we visited, to facilitate access, but with a request to 
include the provost or president; engineering dean; an associate dean; department heads from two different departments (fast changing \& traditional); tenured faculty; untenured faculty; lecturer; and academic advisor. The interview questions were kept consistent across subjects with the periodic modifications indicated below to enable comparison across institutions and organizational scale; follow-on questions were used to collect empirically rich data pertaining to the knowledge, experience, perspective, and available articulations of the behavior of each interview subject.

The project team - consisting of four faculty members, a postdoctoral researcher, two graduate students, and several undergraduates spanning five different academic institutions - meets biweekly to compare notes and analyses. These meetings support our exploratory protocol by having researchers review the interview data, identify relevant phenomena, and iteratively modify the interview questions and subject selection to probe into the different aspects of governance necessary to characterize the U.S. engineering education system as we come to understand it. Thus, as data from the project is analyzed, small adjustments are made to our semi-structured interview protocol and selection criteria. The team is using MAXQDA for analysis and coding. The project uses a grounded theory approach to help identify theoretical artifacts relevant to an understanding of higher education governance as it applies to the complex U.S. ecosystem for engineering education. As analysis of the interview data has begun, several social theories have surfaced that show promise of explaining aspects of this complex system. Among those most germane to our analysis are theories pertaining to professional configurations [4-8]; organizational behavior, scale, and linkages [9-14]; epistemic cultures [15]; the extension of epistemic practices from one domain (engineering practice) into another (educational governance) [16]; and an overall ethnomethodological framework necessary for a close study of educational and institutional reform practices [17-19].

Throughout this iterative research design, some of the most interesting phenomena to emerge out of our data include the ways in which practices of educational reform are encoded into the bureaucratic structure of organizations; how the instrumental conception of engineering knowledge leads educators and educational policy makers to deploy these practices to adapt educational systems to "changing times and needs"[20]; how the distributed structure of the profession and the educational field makes coordination difficult beyond the level of any single institution or organization; and how significant shifts in the national economy, such as the Cold War or the rise of economic globalization force institutional actors into coordinated action, this through substantially improvised processes that enable coordination across institutions. These phenomena, visible in our project at large, play a significant part in the evolution of ABET as a higher education governance entity.

\section{Historical View of the Organizational Structure of ABET Accreditation}

As stated previously this paper presents initial findings resulting from our interview data on the role that ABET plays and has played in the governance of engineering education. Because the U.S. approach to engineering accreditation emerged out of, and continues to be shaped by the organization's long history, this paper is organized around a historical narrative of the events that gave rise to this system. This section of the paper provides insights into that history, extending what is generally known about the history of ABET [21-22]. Specifically, interviews 
of current ABET staff and administrators as well as individuals who were central to some of the major changes ABET has undergone (such as the transition to EC 2000 and the more recent changes in criteria approved by the ABET Board of Delegates in 2017) were conducted to provide a more complete picture of how these changes occurred. The historical account offered below, as built on insights from our interview data, extends what is known about our current accreditation system, and how ABET's governance structures have changed over time.

\section{Early History}

ABET was founded in 1932 as the Engineers' Council for Professional Development (ECPD). Set up intentionally as a "conference-style" organization, it was the tension between the engineering professional societies that dictated that ECPD accreditation would occur by individual degree program, not institution [22].

The first major shift in U.S. engineering accreditation practices occurred after World War II as a response to the ascending stature of the physical sciences. While the Grinter Report is often cited as the origins of engineering education's Cold War turn to "engineering science," the architect behind the report was Cornell University Dean of Engineering, Solomon Cady Hollister. In 1951 Hollister served simultaneously as the chair of ABET's precursor, ECPD's Education Committee, and President of ASEE. As the chair of the Education Committee, Hollister asked ASEE to conduct a general evaluation of engineering education, and then steered the study in a specific direction by conveying that ECPD was willing to consider quantitative accreditation standards. In an era when a majority of engineering schools did not yet have extensive offerings in engineering science, quantitative standards were the quickest way of getting U.S. engineering schools to accommodate the perceived curricular needs of the Cold War era [23].

\section{EC 2000's Origins}

The Cold War consensus favoring the engineering sciences generally held into the 1970s. Nevertheless, as concerns about U.S. manufacturing productivity and national competitiveness grew during the 1970s and 1980s, there emerged a sense that the U.S. was winning one front of the Cold War, only to be falling behind on the other. While not all U.S. colleges and universities embraced the engineering sciences as strongly as others, there was still a perceived imbalance [24].

One account of EC 2000's origins can be found in an early participant account of EC 2000 and its impacts [25]. In our study, we deploy insights from organizational behavior to offer a more nuanced understanding of change processes, such as the organizational inertia that both limit and channel institutional responses. To begin with an example outside of ABET — but of an organization that played a key role in coordinating ABET's stakeholders - the early responses of the National Science Foundation are indicative of this particular phenomenon. Faced with the purported successes of Japanese industrial policy and planning, NSF, along with other federal agencies, shifted towards more targeted funding strategies [22]. The educational component of the Engineering Research Centers was one manifestation of this turn, but in being built around a research-centric framing, their focus was primarily graduate education, undergraduate research, or K-12 outreach [34]. On the other hand, the practice of targeted funding also enabled NSF to also refocus their priorities, resulting in the Engineering Education Coalitions. Six coalitions were established beginning in 1990, each funded to the tune of $\$ 15$ million [26-27]. But while 
the EECs were not exactly a failure, they were perceived and presented as not being a resounding success. In extending the purposeful evolution of funding priorities, NSF's incoming director, Joseph Bordogna began to look for broader possibilities for intervention, with a focus on the phrase, "innovation through integration." Bordogna and his co-authors of a JEE article were among those who pointed to quantitative accreditation standards as a significant reason for the stagnation of US engineering curricula [28]. By allowing faculty to focus on delivering specific content, little attention was given to how students integrated and applied this knowledge.

NSF was hardly the first or only institution to notice this fact. Given the prevailing concerns about national competitiveness, universities were making, or attempting to make various changes in their programs in response to industry demands. Although our interview data is less specific than we might wish on this score - the strongest, public articulation of industry demands occurred after the passage of EC 2000 [29] — it is clear that the early phases of economic globalization drove many large firms to call for significant changes and increased flexibility in engineering education and curricula. However, rapid technological change also exacerbated engineering's perennial bout with curricular compaction, forcing ABET to expand rather than simplify its accreditation criteria. It is said that ABET's general criteria went from less than a page in 1959 to "more than nineteen pages of smaller type" by the 1990s, despite widespread calls for flexibility [25]. This produced a situation ripe for accusations of "bean counting," and increasingly antagonistic encounters between ABET and the programs undergoing accreditation [30].

This said, ABET could find no simple way forward. Given that it had been set up as a delegate based organization, ABET's governing body remained divided as to the appropriate response to national competitiveness. IEEE, in representing a fast-changing field, favored a continued emphasis on the engineering sciences and an educational system that leaned towards research. ASCE, by contrast, occupied the opposite extreme. ASME appeared to be internally divided between those who wished to emphasize manufacturing and research. An organization with over 50 delegates representing 27 engineering professional societies, the ABET Board, as it was then constituted, was not a body that was set up for quick and decisive action [30].

In the participant account offered by ABET's President during this period, John Prados [25], Prados identifies the main impetus for change to be the "big 10 schools"- a group dominated by large undergraduate state institutions - along with ASEE's Engineering Deans Council. In a letter directed to Prados, these deans signed a collective letter threatening their withdrawal. Further impetus then came from industry. While industry had no direct representation in ABET, they began approaching ABET with a united front as the widespread discontent of their university partners became apparent. Their views would eventually find its most coherent expression in a widely circulated paper by McMasters and Matsch on the "Desired attributes of the engineering graduate"[29].

This was sufficient for Prados to take action. Acting as the organization's President, Prados challenged his Board of Directors to "consider radical revisions in accreditation philosophy, criteria, and procedures,"[25] leading to the formation of an Accreditation Process Review Committee in 1992, which he chaired. APRC enabled ABET to establish direct dialogue with diverse stakeholders. Finding in this dialogue an opportunity for intervention, NSF provided the 
funds that were needed for a series of "consensus building" workshops involving over 125 participants. The Criteria Workshop focused on the issue of existing accreditation criteria; the Process Workshop focused on the adversarial relationship between ABET and academic institutions; and the Participation Workshop was organized around stakeholders, including many representatives from industry [25, 31]. While NSF's influence, as a funding agency, remained arms-length, from the standpoint of educational governance and a national capacity for directing change in engineering education, NSF's interest and capacity to fund consensus workshops was nevertheless a vital instrument for change.

\section{Changing ABET}

Still, although the NSF-funded workshops provided a road map, Prados had to drive the conversation through ABET, which had its own organizational structure and rules of procedure. Despite the Board's support, ABET remained a delegate style organization in a divided profession. Fearing that working exclusively through the established governance structure might lead to impasse, Prados assembled a group of actors, an "ad hoc committee" that would come to be known as the Gang of Six. Including Prados, this consisted of the new Executive Director, George Peterson; Ed Parrish, the President of WPI; Ira Jacobson, the incoming chair of the Engineering Accreditation Commission's (EAC) Criteria Committee; Dayne Aldridge, an associate dean at Auburn University; and Richard Seagrave from Iowa State. Not only were these individuals seasoned administrators, but a prosopographic study of these individuals also reveals a solid commitment to the applied turn in U.S. research universities [25].

Given that the focus of the reform was on developing a new accreditation standard, the bulk of the work fell on Jacobson's committee. Jacobson developed a protocol for how his committee would go about discussing potential changes, which helped align its members to the shared vision that had emerged out of the stakeholder workshops. But it is also significant that ABET commissioners, of whom the Criteria Committee members were a part, were already substantially aligned to ABET and its mission, as opposed to the professional societies that they were appointed from. Unlike the Board of Directors, whose role it was to represent the member societies, EAC commissioners had significant operational responsibilities, specifically for leading accreditation visits and ensuring consistency. In practical terms, this meant that they were familiar with, and functionally aligned with the mission of the organization and its need for having a workable standard. As further evidence of their loyalty, Jacobson's committee met on a biweekly basis for over a year, threatening each other with more chicken dinners if they failed to make progress [32-33]. (To read this from the register of governance, could you imagine this as the mechanism for compliance in Soviet Russia?)

Outcomes assessment was already brought up during the Criteria Workshop [31]. Quality control and continuous improvement were broadly discussed during the 1980s and early 90 s amidst concerns about national competitiveness. Initiatives such as Six Sigma (a well-known set of techniques for process improvement) and the Baldridge Awards (a national quality award issued by the US President) were widely talked about in engineering circles, and it followed that performing assessments in some manner was necessary to drive improvement. In following his broader disciplinary practice as an academic engineer, Jacobson canvassed the literature on assessment and reported on what he found. He found that higher education, and education in general was talking about outcomes assessment. Regional accreditation agencies were talking 
about shifting to it, even as nursing and business were already moving towards implementation [33-34]. Learning outcomes were also being discussed in K-12 education, although they had not yet seen widespread implementation in the United States. Once this was known, the idea of outcomes assessment and continuous improvement became central to Jacobson's committee's deliberations. There is no clear recollection of how the group moved from here to the first set of a-k learning, or "program" outcomes as it was originally called [32].

\section{Criterion 3. Program Outcomes and Assessment}

Engineering programs must demonstrate that their graduates have:

(a) an ability to apply knowledge of mathematics, science, and engineering

(b) an ability to design and conduct experiments, as well as to analyze and interpret data

(c) an ability to design a system, component, or process to meet desired needs

(d) an ability to function on multi-disciplinary teams

(e) an ability to identify, formulate, and solve engineering problems

(f) an understanding of professional and ethical responsibility

(g) an ability to communicate effectively

(h) the broad education necessary to understand the impact of engineering solutions in a global and societal context

(i) a recognition of the need for, and an ability to engage in life-long learning

(j) a knowledge of contemporary issues

(k) an ability to use the techniques, skills, and modern engineering tools necessary for engineering practice.

Figure 1. An early version of EC 2000's a-k student learning outcomes [35].

The most significant thing to note about EC 2000 is their overall emphasis on professional skills (see Figure 1). Of the eleven a-k learning outcomes, at least seven, and arguably nine had to do with professional skills. Only (a) and (b) deal exclusively with technical content. And while engineering educators would welcome humanities and social sciences faculty who were willing to work to integrate these learning outcomes into their courses, Jacobson's committee understood that the academic politics surrounding general education required the change to be accomplished, in large measure, through courses taught by the engineering faculty [33].

This said, EC 2000 was also built around a set of political compromises. The Gang of Six spoke casually about having three broad goals: the first was to come up with a radically simplified accreditation criteria; the second to get rid of program criteria; and the third to get rid of the commissions. But as much as Jacobson's committee remained aligned with Prados and his vision, they recognized that none of the professional societies would approve the elimination of program criteria [32]. They also chose to maintain the rough outlines of a quantitative criteriathe requirement that all engineering programs have a year of math and science; one and a half years of "engineering topics"; and in addition, a culminating design experience that would require them to incorporate the knowledge and skills they acquired through prior coursework [35]. The purpose of Criterion 4 (originally labeled "Professional Component") was to guarantee that the emphasis on technical training was not sacrificed through this new emphasis on professional skills. The committee knew that the EAC would not accept EC 2000 without this 
guarantee [32]. The phrase "engineering topics" did, on the other hand, allow programs to differentiate themselves between those that wished to emphasize engineering design and practice as opposed to the engineering sciences [31-32].

EC 2000, as originally drafted, also placed significant emphasis on program education objectives [35-36]. While it remains unclear how even individual members from Jacobson's committee understood the purpose of Criterion 2, the basic idea was that programs could build all of their learning outcomes around the specific institutional context and program objectives that were defined, in turn, according to the "needs of the program's various constituencies."[35] Thus, minority serving institutions seeking to address the challenges of diverse preparation could, for instance, define learning outcomes consistent with their student population. Large state universities seeking to expand enrollment to address state funding imbalances could define learning outcomes in a way that supported their enrollment and retention targets. And theoretically, elite institutions that offered greater curricular flexibility by dividing their program into "options" could present and assess different learning outcomes consistent with each option. It was understood that these assessments had to be "mapped back onto a-k" to simultaneously demonstrate the achievement of minimum standards, but the emphasis, originally, was not only on meeting minimum standards, but promoting educational improvement, differentiation, and indeed innovation $[28,35]$.

Also relevant to a more fine-grained understanding of educational governance practices is the fact that Jacobson ran the Criteria Committee's deliberations under a veil of secrecy. This was done to limit external influence. However, this also meant that EC 2000 was introduced to the EAC in June of 1995 with little attention to assessment. Assessment, or rather the accreditation process, was being discussed separately by a group chaired by Aldridge, another member of the Gang of Six, whom Jacobson kept in the dark [34]. Even while supporting the proposal when he saw it, Aldridge wondered how it would be possible to implement the idea in practice. Yet, despite widespread concerns about feasibility that were initially expressed, the EAC deliberations also shifted onto the familiar terrain of debating disciplinary expectations and differences [37]. This was territory that the Commission's leadership could cover by pointing to the Criterion 4 compromise (Criterion 5 [curriculum] today) as well as the continuation of program criteria. The EAC and Board leadership could also point to the urgency of their recent crisis and their promise to be responsive to stakeholders.

Given the radical nature of the proposed changes, the Board initially announced that there would be a two-year comment period during which all stakeholders could comment on the proposal. However, after one year, during which the EAC and its Criteria Committee made appropriate changes, the Board, in continuing to improvise upon its own governance procedures, decided instead to place EC 2000 on a two-year trial period. Most of the continued comments related to concerns about feasibility that could not be folded into a solution, and trial by fire appeared to be the best way to assess the feasibility of outcomes assessment [33].

The Evolution of Outcomes Assessment

EC 2000's historic significance, and what it says in turn about educational governance in the United States, rests not only on its approval, but how outcomes assessment played out in practice. Not surprisingly, it was Aldridge who was the first to discover the challenge ABET 
faced going forward. Being an associate dean at Auburn's College of Engineering, he could see the implications of assessment from the point of view of an institution seeking accreditation. Some of those who expressed concern about EC 2000 had reached out to colleagues in their school of education, only to find that they had little to share. K-12 was headed towards a more straightforward testing regime, as opposed to the assessment of complex and institutionally selfdefined learning outcomes [34].

This said, the initial trial visits unfolded mostly as expected: two in the first year, three in the second [25]. The first two visits were with WPI and the University of Arkansas, intentionally a small, private engineering school and a large state university. Both were friendly to EC 2000; Parrish was a member of the Gang of Six and President of WPI. Jacobson's co-chair, Joe Sussman, led the visit to WPI, sending the team there before the official visit in order to work together with the WPI faculty and administration to develop an assessment protocol that they themselves would evaluate. While descriptions of this visit reveal a general lack of familiarity with assessment, they also point to the thoughtful collaboration between the two parties. It was understood from the outset that ABET would "hold harmless" the early group of institutions that agreed to participate in accreditation under EC 2000, especially WPI and Arkansas. Both institutions were also selected specifically because they had an impeccable accreditation record [32]. Based on the two year trial period, the ABET Board approved a phased roll out of EC 2000, making it optional for three years starting with the 1998-1999 accreditation cycle, and mandatory thereafter.

Aldridge stepped forward to help universities transition to outcomes assessment. Aldridge had some support from a philanthropic foundation that gave him free reign to explore whatever topic in engineering education he cared to study, and secured an invitation from the American Association of Colleges and Schools of Business (AACSB) to join an accreditation team on one of their early visits. During the visit, Aldridge realized that AACSB, and by extension ABET was making a grave mistake by not preparing faculty and university administrators for the accreditation visits; outcomes based accreditation would soon collapse for AACSB. Working with the Gang of Six, and with additional funds from NSF, Aldridge organized a series of 12 regional workshops that engaged several hundred faculty members to learn the purposes and requirements of EC 2000. Assembling faculty, not administrators, with a demonstrated interest in undergraduate teaching, Aldridge worked to develop a cadre of teaching faculty across different institutions who understood and believed in outcomes assessment. These workshops were crucial to building on-the-ground interest and support for EC 2000 and outcomes assessment as a whole. It was also around this time that Gloria Rogers, an education specialist working with Rose Hulman, got involved. Rogers picked up the material Aldridge developed, and began offering assessment seminars, along with others, as ABET contractors [34].

Still, the wording of EC 2000 criteria remained ambiguous, or at least unfamiliar and difficult to interpret for many, leading to varied implementations, and confusion. A common early error was programs that collected too much data. Perhaps promulgated by early statements from ABET itself, institutions required all of their instructors to assess learning in all of their courses, generating volumes of data that were never analyzed. There was also confusion regarding direct and indirect measures, and what counted as valid assessment. On the other end of the spectrum, there were programs that took the protocol very seriously, only to find that ABET's program 
evaluators were insufficiently trained to properly recognize and evaluate such efforts. Most notably, many programs learned to present some proximate measure that demonstrated some competence in each student outcome, resulting in a situation where PEVs had to exercise judgment about what constituted an adequate measure of a stated learning outcome. This too inserted uncertainty into the program evaluation and overall accreditation process [30].

The evolution of EC 2000's implementation has been as much about the unrecorded conversations and distributed negotiations between academic institutions, program evaluators, and EAC commissioners that produced subtle yet definite shifts in assessment practice. The most notable change has been ABET's willingness to accept whatever assessments institutions put forward, so long as the institution demonstrated what evaluators felt were earnest efforts to measure some aspect of each a-k learning outcome. This was consistent with the understanding that programs were supposed to be free to target assessment around outcomes that aligned with their own objectives. It was, at the same time, a tacit acceptance of the fact that program evaluators who visited a program they never saw before were hardly in a position to judge whether a specific assessment mapped onto the current goals of an institution and their stated program objectives [34].

It is probably in light of this shift towards proximate measures that ABET shifted their emphasis towards continuous improvement. Again, continuous improvement was central to the very development of EC 2000. However, most programs undergoing accreditation did not embrace it with the same enthusiasm as the committee that developed it. Over time, ABET has come to place greater emphasis on "closing the loop," which is another way of ensuring that all institutions are moving closer to the required student outcomes. The continuous improvement requirements of ABET are evolving, so it is too early to assess whether this has contributed substantially to the strengthening of U.S. engineering programs. However, as pointed out by one interviewee, so long as there is no standard measure for determining how much improvement constitutes acceptable improvement, the efficacy of the approach remains dependent on how much academic institutions engage with the idea of continuous improvement [33-34].

\section{Insights into Current Practices and EC 2000's Impact}

The above history extends our understanding of how institutional processes and key individuals produced major changes in our system of engineering accreditation; through this, we gained new insights into what educational governance looks like in the United States, with regards to ABET accreditation. Formally, this system of governance also operates through its extension into the routine assessment practices of the institutions seeking accreditation. As recognized by those who developed EC2000, in order for continuous improvement to be the mantra of ABET and an "American" approach to accreditation, it is essential for programs to take full ownership of the process, and to develop assessment protocols designed to address real challenges within their own educational programs. This is all the more important because, as mentioned in the introduction to this paper, American universities are highly diverse and serve a wide range of different student and stakeholder needs.

Our interviews have documented institutional responses to EC 2000 at a diverse array of institutions, with attention to differences across organizational levels: individual faculty, 
curriculum committee members and department heads, and senior administrators. This data serves as a means of validating the historical changes in accreditation practice reported above, even as it provides a broad-gauge map of the variations in assessment practice as found within U.S. engineering schools today. As a qualitative study of a highly distributed system covering an entire nation, these results are necessarily incomplete. However, they do offer a description of some common responses, which might serve as the basis for a more comprehensive quantitative survey. The following is also based on an aggregate analysis of the data, and does not identify specific individuals or institutions. A more detailed analysis of the interview data that describes further nuances and variation within each type of response will be reported separately.

First, there are a handful of institutions, especially at top tier undergraduate teaching institutions, that choose to practice assessment as it was originally designed. They develop their own program objectives, define their own learning outcomes based on them, and map them onto the a-k (now 1-7) outcomes to demonstrate compliance. They have, in addition, fully merged their own process for continuous improvement with those required by ABET, both at program and course level, making sure to incorporate the outcomes assessment requirements of ABET into their assessment protocol. However, within our data set there are at least two institutions that have scaled back their assessment efforts out of their sense that program evaluators do not have sufficient training to acknowledge such efforts and exercise appropriate judgment in the evaluation of their programs.

Meanwhile, there are many lower ranked institutions for whom ABET accreditation is considered important, especially to their image and recruiting initiatives. While many admit that parents rarely ask about accreditation, engineering accreditation is generally viewed as necessary at all state institutions, and this regardless of rank. Minimum standards also serve a purpose at lower ranked institutions, since they often need to work to meet ABET's requirements. In this context, a shortcoming - ideally a concern, or at most an initial report of a weakness that can be addressed before the final decision - can be instrumental for deans and department heads to garnering resources, such as faculty lines and better laboratory facilities, needed to maintain accreditation. In addition, in regions experiencing economic and demographic growth, ABET requirements have sometimes served as a useful template for getting new engineering programs off the ground.

The most common strategy that we have found is that of compliance. Whether because an institution felt that their program was superior to ABET's minimum standard, or because they felt they had internal improvement processes that were better, many institutions have developed assessment protocols that are simply designed to demonstrate compliance. Embedded in the latter is the idea that ABET's learning outcomes, and what it requires in terms of assessment (although a specific process is not mandated) do not map onto the real improvement these programs hope to make. Perhaps appropriately, programs seeking only to demonstrate compliance experience anxiety over how their evaluation will play out. The frequent rotation of the individuals who oversee assessment, both at department and college level without sufficient attention to institutional memory, contributes to this problem. While anxiety may be a consequence of these institutions' limited engagement, it nevertheless contributes to institutional doubts about the merits of assessment. There are also some variants, including institutions that 
maintain independent processes that have nevertheless found ways to use the assessment and data collection they do for ABET as inputs into their internal processes.

Finally, there are a handful programs that are considering dropping ABET accreditation. On the surface, the main argument presented by these programs, typically at top ranked universities, is that ABET's curricular requirements lack flexibility. They, along with others, view ABET as once again preventing curricular innovation. Generational issues may be at play here as well. Research faculty at top institutions often view their expertise as spanning multiple disciplines, even as students have come to regard AI, data analytics, and other subjects related especially to computer science as essential for strong internships and placement. However, the volunteerbased approach to accreditation practiced by ABET, which was made necessary by the historic decision to conduct accreditation by degree program rather than institution, has ensured that many ABET volunteers are older, retired, and tend to have more conventional views about their discipline.

The point of contention here is really about Criterion 5 (curriculum), not Criterion 3 (student outcomes). Given the authority program evaluators are given to exercise judgment in deciding what content is appropriate to their discipline, attitudinal differences can produce different and inconsistent evaluation results. While it is generally understood at commission level that program evaluators need to be selected to be appropriate for the institution they are visiting, when this fails to occur, or when the faculty from programs seeking accreditation have a poor understanding of ABET or even their own institution's approach to assessment, accusations of "bean counting" once again surface. The emphasis on continuous improvement has sometimes also contributed to the conflict, as evaluation teams were seen by some as lacking the necessary background to conduct the evaluation, and for having a "chip on their shoulder" simply by insisting that continuous improvement should be possible even at the best institutions. While the latter is in fact true, what this rejoinder fails to recognize is the extent to which the competitive environment of top R1 institutions force their faculty to value their time. With their focus on research and graduate education, and especially at institutions where ABET processes are regarded as a matter of compliance, outcomes assessment as a means of driving continuous improvement is felt by some to be an ineffectual way to bring about change. ABET's Engineering Accreditation Commission is aware of these issues, and is considering ways to modify its internal procedures and the guidance it offers to team chairs. We should also add that there are many extremely highly ranked institutions who participate willingly in ABET, viewing it as an obligation to the profession. Some programs have also shifted to general engineering accreditation to enable greater flexibility, although this practice may not always be compliant with ABET's naming requirements for academic programs.

If the above descriptions are representative of current practice, what was the overall impact of EC 2000? In continuing to draw on our data to answer this question, when asked to reflect on the changes that have occurred, many interviewees remark that faculty today do pay greater attention to undergraduate education, and participate in more regular, if not always continuous improvement efforts both at course and program level. Indeed, individuals from many different institutions, regardless of position or institutional rank, mentioned that conversations in the departments and colleges that were stimulated by an ABET visit were helpful. (This said, many institutions still rush to compile their ABET data two to three years before a visit.) Many of those 
interviewed also admit that curriculum changes, especially at program level, were a more infrequent occurrence prior to EC 2000. Many also feel that EC 2000's primary impact was the expanded emphasis on professional skill sets. Engineering faculty have incorporated teamwork, design, and communication into their technical classes, as was intended with EC 2000, although we still need to consider those a-k outcomes that engineering faculty have not significantly embraced.

\section{The Latest Revisions \& Board Reorganization}

At the start of our study, we paid considerable attention to the latest round of revisions to the ABET engineering accreditation criteria, the one approved by the ABET Board of Delegates Engineering Area Delegation in 2017 [39]. While we tell this story only briefly here, there is also an interesting case study in organizational behavior here, one directly related to the question of governance: when the responsibility for change was placed in the hands of a group of reformers intent on transforming engineering education to match new global economic realities, there was a strategic vision and an uncommon degree of coordination both within and across organizations. However, the latest changes that began around 2007 were driven instead by operational concerns due to the continuing discontent expressed by programs undergoing accreditation. Moreover, once the reevaluation of accreditation criteria were placed in the hands of a group at least two levels down within the organization, very different recommendations emerged. We focus here on the initial recommendations of the Criterion 3 Task Force, recognizing that they were vetted and substantially amended before assuming their present form.

Academic institutions continued to press ABET in the wake of some actions ABET took - $\mathrm{a}$ meeting at WPI in 2002 [39], and a commissioned Penn State study on ABET's impacts, which was released in 2005 [40]. While many programs had indeed embraced communication, teamwork, and the various professional skills associated with design, other professional skills such as lifelong learning and knowledge of contemporary issues found little headway at a majority of the nation's engineering programs. The requirement for multidisciplinary teams was also a significant point of concern. Most programs continued to run their senior capstones as a departmental activity, and hence there was little interdisciplinarity to draw on in their senior design studios. In the words of one of our interviewees, this particular outcome hung over their heads like the Sword of Damocles [30]. While ABET was firmly moving towards accepting the choices that institutions made with regards to what assessments they employed, those seeking to simply demonstrate compliance had reason to be anxious, since any deficiency could bump an institution from the desired "NGR" (next general review), or full six-year accreditation, and program evaluators were, by design, given the authority to exercise such discretion [37].

By 2009, there was sufficient pressure for change for the EAC to proceed with a reevaluation of Criterion 3. The Commission constituted the Criterion 3 Task Force, which was instructed to consult with various constituencies, review program evaluation data, and recommend changes that they deemed necessary and desirable. Their study of the program evaluation data confirmed their suspicion that programs were experiencing difficulty demonstrating certain outcomes. At the same time, consultation with constituencies produced 75 new suggestions for learning outcomes [32, 41-42]. Instructed as well to find a way to encourage more innovation, and by implication, the associated demand for flexibility, the task force came up with the idea of placing 
all of the learning outcomes into five skills "buckets" that focused on professionalism; technical, business, and communication skills (comprising three of the buckets); and other "individual" skills such as creativity, leadership, innovation, and ingenuity [43]. The idea was each program would come up with just one outcome related to each bucket that it would assess for an accreditation visit, while encouraging or requiring the programs to assess other outcomes specific to their program. However, in recognizing that such a change might not secure the EAC's approval, the task force also offered an alternative that carefully considered each outcome, with attention to those outcomes that programs were having the greatest difficulty meeting. Along with other changes and improvements in language, this produced an initial list containing just six learning outcomes.

The Task Force delivered its recommendations at the July 2013 meeting of the EAC [44]. Many of the professional skill sets that were removed by the Task Force were subsequently reintroduced, albeit through the use of "combined criteria." $[35,44]$ While the consequence of this change is still being discussed, it is worth considering separately the response of an industry representative who spoke during a National Academy of Engineering forum organized to discuss the change [45].

Dianne Chong, an EAC member, but also a retired executive from Boeing, stated that the revised criteria in its more recent form, "agree very well with what she has heard from various corporate department heads about what they need from every engineer they hire."[45] There was no sense of alarm about a change in direction. While this may have simply been Chong's affirmation of the Criteria Committee's responsiveness, the other way to read her statement is to take it as an indication of the industrial employers' general satisfaction with the changes that had occurred since EC 2000. As echoed in many of our interviews, engineering graduates today appear to be more willing to embrace the professional dimensions of their work, are accustomed to doing presentations, are interested in design, and are all too familiar with, if not always pleased with group work. In this respect, ABET's efforts to meet all of the different "desired attributes" of an engineering graduate, as expressed through a list of measurable (or in the views of some, immeasurable) outcomes, may have been more of ABET's own making. It may have had more to do with their epistemic habits as engineers, and not necessarily what industry was really looking for. While some have asked whether the new criteria represented "watered-down gen ed for engineers," [46] that kind of vision for deeper engagement with the liberal arts was likely never a priority for employers, or ABET. Industrialists were simply happy that universities had in fact made a shift in response to broader changes in the national economy.

\section{Summary \& Conclusions}

As mentioned earlier, this paper is part of a larger project looking at governance structures in U.S. engineering education. It has presented preliminary findings looking at how U.S. engineering accreditation processes changed over time, and what this reveals about higher education governance in the U.S. as it relates to our education of engineers. Since all the interview data from key players in the policy domain have not been collected or analyzed these results are somewhat preliminary, but several key conclusion are beginning to emerge. The findings here relate most directly to ABET and its relationship with U.S. universities and colleges: 
- In the United States, governance of engineering education occurs through a loose system of coordination. Role differentiation on the part of different organizations, including universities and professional societies enable engineering education and its reform efforts to take on diverse manifestations. This complex institutional ecology for engineering education is considered to be among the strengths of the U.S. system, where flexibility and innovation are often presented as desired characteristics, despite expressing a simultaneous commitment to professional standards. This creates challenges for an organization such as ABET, which many perceive to have a role defined primarily by determining and enforcing minimum standards.

- This said, engineering educators view engineering as an instrumental form knowledge, and strive to change engineering education to meet changing times and needs. Within the field of engineering education, there are entities such as ABET, as well as undergraduate committees at academic institutions who work regularly, if not continuously, to change engineering education. Because each operate under separate processes and associated governance structures, these processes can come into conflict, as they did prior to EC 2000, and for some universities, at present.

- Embedded within these processes is an extensive array of ordinary everyday actions, as defined, for example, through the different approaches universities adopt for assessment; bureaucratic rules of procedure regarding accreditation and accreditation visits; the process by which curriculum committees operate; the formal and informal rules of conduct of ABET's committees, commissions, and governing board(s); and even the strategies for collective action and resistance designed to drive or circumvent change. All of these actions contribute to educational improvement and transformation. As much as some of these actions appear to be specified, say, by organizational rules of procedure, there is also a good deal of improvisation involved in making change happen. Failure to anticipate responses and to properly read the context for one's work can also lead a group to partially or wholly lose control of a change process, as demonstrated by the early recommendations of the Criterion 3 Task Force, or the failed efforts of the AACSB.

- In this account, there were also distinct moments when the epistemic commitments of engineering educators, as engineers, influenced how and by what means they pursued their change initiatives. The quantitative approaches and quest for certainty that are found repeatedly in this account - the desire to remove those outcomes that institutions were finding most difficult to achieve and demonstrate, for instance - affirm and extend Seron and Silbey's observations about how the epistemic commitments of engineers inform their approach to educational governance and reform [16].

These results, along with new insights as the project continues, will be used to develop recommendations to ABET. The insights that this study can ultimately provide will likely be related to: ABET's use of learning outcomes to drive educational change; what actions would be needed to make continuous process improvement function as ABET intends; and possible changes in its governance structure necessary for it to be able to take such action. However, these recommendations are still being formulated and will be difficult to convey compellingly until the 
study is complete. Because of the potential effect such recommendations may have, these preliminary results are being presented here to stimulate feedback and bring more voices into the project's iterative framework.

\section{Acknowledgements}

This material is based upon work supported by the National Science Foundation under grant numbers SES-1656125, 1655750, and 1656117. Any opinions, findings, and conclusions or recommendations expressed in this publication are those of the author(s) and do not necessarily reflect the views of the National Science Foundation. We also extend our deepest appreciation to the current and past officers, staff, and volunteers of ABET who contributed to this paper, without whom this account would not have been possible.

\section{References}

[1] B. L. Berg, Qualitative Research Methods for the Social Sciences (4 ${ }^{\text {th }}$ ed.). Boston, MA: Allyn and Bacon, 2001.

[2] A. Strauss and J. Corbin, Basics of Qualitative Research: Grounded Theory Procedures and Techniques, $2^{\text {nd }}$ edition. Newbury Park, CA: Sage Publications, 1990.

[3] J. M. Corbin, and A. Strauss, Basics of Qualitative Research: Techniques and Procedures for Developing Grounded Theory, $3^{\text {rd }}$ edition. Thousand Oaks, CA: Sage Publications, 2008.

[4] E. Layton, Revolt of the Engineers: Social Responsibility and the American Engineering Profession. Cleveland, OH: Case Western Reserve University, 1971.

[5] A. M. McMahon, The Making of a Profession: A Century of Electrical Engineering in America, 1880-1980. New York: IEEE Press, 1984.

[6] B. Sinclair, A Centennial History of the American Society of Mechanical Engineers, 18801980. New York: American Society of Mechanical Engineers, 1980.

[7] T. S. Reynolds, Seventy-Five years of Progress: A History of the American Institute of Chemical Engineers, 1908-1983. New York: American Institute of Chemical Engineers, 1983.

[8] D. F. Noble, America by Design: Science, Technology, and the Rise of Corporate Capitalism. New York: Alfred P. Knopf, 1977.

[9] D. A. Nadler and M. L. Tushman, "A model for diagnosing organizational behavior," Organizational Dynamics, vol. 9, no. 2, pp. 35-51, 1980.

[10] M. Aiken and J. Hage, "Organizational interdependence and intra-organizational structure." Am. Soc. Rev., pp. 912-30, 1968.

[11] P. S. Goodman, Missing organizational linkages: Tools for cross-level research. Thousand Oaks, CA: Sage Publications, 2000.

[12] J. Knoben, "Localized inter-organizational linkages, agglomeration effects, and the innovative performance of firms," Ann Regional Sci., vol. 43, no. 3, pp. 757-79, 2009.

[13] C. Huxham, "Collaborative capability: An intra-organizational perspective on collaborative advantage," Publ. Money \& Mgt., vol. 13, no. 3, pp. 21-28, 1993.

[14] M. Holmqvist "A dynamic model of intra-and interorganizational learning," Org. Stud., vol. 24, no. 1, pp. 95-123, 2003.

[15] K. Knorr-Cetina, Epistemic Cultures: How Sciences Make Knowledge. Cambridge, MA: Harvard University Press, 1999. 
[16] C. Seron, and S. Silbey, "The dialectic between expert knowledge and professional discretion: accreditation, social control and the limits of instrumental logic," Eng. Stud. vol. 1, no. 2, pp. 101-27, 2009.

[17] H. Garfinkel, Studies in Ethnomethodology. Englewood Cliffs, NJ: Prentice-Hall, 1967.

[18] J. Heritage, Garfinkel and Ethnomethodology. Cambridge: Polity Press, 1984.

[19] A. Pickering, The Mangle of Practice. Chicago: University of Chicago Press, 1995.

[20] A. Akera, "Understanding the practice of engineering education reform: The investigative traditions of the American Society for Engineering Education, 1907-1968," ASEE Ann. Conf. and Expo., June 2008 (Pittsburgh, PA).

[21] M. Lynch, Scientific Practice and Ordinary Action: Ethnomethodology and Social Studies of Science. Cambridge: Cambridge University Press, 1993.

[22] A. Akera, "Setting the standards for engineering education: a history," Proc. IEEE, vol. 105, no. 9, pp. 1834-1843, September 2017.

[23] A. Akera, "The practice and discursive constructions of engineering education reform: ASEE Committee on Evaluation of Engineering Education, 1952-1955," Proc. Int'l Network for Eng. Studies Fall 2016 workshop: Locating Engineering: Education, Knowledge, Desire, Blacksburg, Va., September 2006.

[24] ASEE, "A national action agenda for engineering education," Report of an ASEE task force. Washington, DC: American Society for Engineering Education, 1987.

[25] J. W. Prados, G. D. Peterson, and L. Lattuca, "Quality assurance of engineering education through accreditation: the impact of Engineering Criteria 2000 and its global influence," J. Eng. $E d$., vol. 94, no. 1, pp. 165-84, January 2005.

[26] J. Meade, "Engineering coalitions find strength in unity," Prism, September 1991, pp. 2426.

[27] R. Coleman, “The engineering education coalitions," Prism, September 1996, pp. 24-31. [28] J. Bordogna, E. Fromm, and E. Ernst, "Engineering education: innovation through integration," J. Eng. Ed., vol. 82, no. 1, pp. 3-8, January 1993.

[29] J. H. McMasters and L. A. Matsch, "Desired attributes of an engineering graduate," AIAA Mtg. Pprs., CD, AIAA Paper 96-2241, June 1996.

[30] Oral interview, project data. Anonymized references, to the extent authorized by the interview subject, are available upon request.

[31] "The vision for change: A summary report of the ABET/NSF/industry workshops," Report. Baltimore, MD: ABET Inc., n.d. [1995].

[32] Sussman interview, 1 February \& 15 February 2018, Project data. In striking a balance between the citation conventions of history and qualitative social science research, citations to oral history sources are provided to the extent to which subjects have agreed to be identified in this study. Citations to specific page numbers from the interview transcripts are available on request.

[33] Jacobson interview, 26 February 2018.

[34] Aldridge interview, 14 February 2018.

[35] ABET, "Criteria for accrediting programs in engineering in the United States for programs evaluated during the 1998-1999 accreditation cycle," [1 November 1997]. Baltimore, MD:

ABET Inc., pp. 47-49.

[36] ABET, "Criteria for accrediting engineering programs in effective for evaluations during the 2010-2011 accreditation cycle," [31 October 2009]. Baltimore, MD: ABET, Inc., p. 3.

[37] Leonard interview, 22 February 2018. 
[38] ABET, "Criteria for accrediting engineering programs," [20 October 2017], Baltimore, D: ABET Inc.

[39] "Sustaining the change," Report. Baltimore, MD: ABET Inc., 2004.

[40] L. R. Lattuca, P. T. Terenzini, and J. F. Volkwein, "Engineering change: A study of the impact of EC2000," Baltimore, ABET Inc., 2005.

[41] ABET, "Criterion 3 revision timeline." [Online]. Available: http://www.abet.org/criterion-3revision-timeline/. [Accessed 11 November 2015].

[42] ABET, "Rationale for revising criteria 3 and 5." [Online]. Available:

http://www.abet.org/accreditation/accreditation-criteria/accreditation-alerts/rationale-forrevising-criteria-3/. [Accessed 11 November 2015].

[43] ABET, "Proposed revisions to ABET criterion 3 and criterion 5," PowerPoint presentation, 2014. [Online]. Available: http://www.ecedha.org/docs/default-source/2015-speakerpresentations/steve-phillips.pdf?sfvrsn=0. [Accessed 3 February 2019].

[44] "Summary of ASEE member views," June 2016. [Online]. Available:

https://aseetownhall.files.wordpress.com/2016/10/summary-of-asee-member-views-revised-

final.pdf. [Accessed 3 February 2019].

[45] R. Pool, "Forum on proposed revisions to ABET Engineering Accreditation Commission criteria on student outcomes and curriculum: a workshop summary," Unnumbered report.

Washington, DC: National Academies Press, 2016. [Online]. Available: https://www.nap.edu/catalog/23556. [Accessed 3 February 2019].

[46] C. Flaherty, "Watered-down gen ed for engineers?" Inside Higher Ed, 26 June 2015. 